\title{
Surface Explosion Chemistry of Malic Acid on $\mathrm{Cu}(110)$
}

\author{
Christian Roth $\cdot$ Karl-Heinz Ernst
}

Published online: 15 October 2011

(C) Springer Science+Business Media, LLC 2011

\begin{abstract}
The thermal decomposition chemistry of malic acid adsorbed on a copper(110) surface was studied with thermal desorption spectroscopy, reflection-absorption infrared spectroscopy, low-energy electron diffraction and $\mathrm{X}$-ray photoelectron spectroscopy in ultrahigh vacuum. In contrast to tartaric acid on $\mathrm{Cu}(110)$, no differences between racemate and pure enantiomers have been identified.
\end{abstract}

Keywords Surface chemistry $\cdot$ Autocatalytic decomposition · Chirality · Thermal desorption spectroscopy

\section{Introduction}

Control of diasteriomeric recognition between enantiomers of different compounds at surfaces is the key route to desired pure enantiomers via crystallization or enantioselective hydrogenation over chiral-modified heterogeneous catalysts $[1,2]$. For the latter, examples are cinchona-modified platinum group metals [3] and tartaric acid-modified nickel [4,5]. These systems provide high enantiomeric excess (ee) for hydrogenation of $\alpha$-keto carboxylic acid derivatives and $\beta$-keto carboxylic acid esters or ketones [6]. It has been demonstrated that studies of well-defined model systems help to unravel details of heterogeneously catalyzed reactions [7]. Consequently, the adsorption of chiral molecules on single crystal surfaces is increasingly deployed as an approach for better understanding of chiral recognition at

C. Roth · K.-H. Ernst $(\bowtie)$

Nanoscale Materials Science, Empa, Swiss Federal Laboratories for Materials Science and Technology, Überlandstrasse 129, 8600 Dübendorf, Switzerland

e-mail: Karl-Heinz.Ernst@empa.ch surfaces [8, 9]. The adsorption and self-assembly of cinchonidine and tartaric acid on single-crystal metal surfaces has therefore been widely studied [10-19]. In particular enantiopure tartaric acid (TA) on $\mathrm{Cu}(110)$ became a popular model system to investigate principles of chirality transfer into 2D crystal structures [15-19]. Similar studies have been performed on racemic TA [20, 21], the achiral meso-TA $(m$ TA) [22], and achiral succinic acid (SU) [23] all on $\mathrm{Cu}(110)$. The prochiral species $m$-TA and SU become chiral upon adsorption and express 2D enantiomorphism. If additional chiral bias is introduced by doping $m$-TA and SU layers with $(R, R)$ - or $(S, S)$-TA enantiomers, one enantiomorphous state is suppressed and homochirality is installed on the entire surface $[24,25]$. A similar effect has been observed at small ee in monolayers of heptahelicene on $\mathrm{Cu}(111)[26,27]$. ee in TA-monolayers on $\mathrm{Cu}(110)$ [28] or malic acid enantiomers mixed into racemic TA monolayers also suppress formation of one mirror domain [29].

The thermally induced decomposition of these butanedioic acids on $\mathrm{Cu}(110)$ is characterized by the so-called "surface explosion" mechanism. This expression stands for an autocatalytic increase in reaction rate in thermally induced surface reactions, occurring in a very narrow temperature range [30]. This has been reported for various systems like formic acid/ $\mathrm{Ni}(110)$ [31], acetic acid/ $\mathrm{Ni}(110)$ [32] and acetic acid coadsorbed with oxygen or carbon on $\mathrm{Rh}(111), \mathrm{Rh}(110)$, and Pd(110) [33-36]. Due to deprotonation of the carboxyl groups these molecules are strongly bound and intact desorption is not possible since the hydrogen has left the surface. At higher temperature, decomposition into products like $\mathrm{CO}_{2}, \mathrm{H}_{2} \mathrm{O}, \mathrm{H}_{2}$, etc. is therefore usually observed. These products are created at temperatures far above their desorption temperature and they leave the surface instantaneously. Since the decomposition is catalyzed by the metal surface, the decomposition temperature 

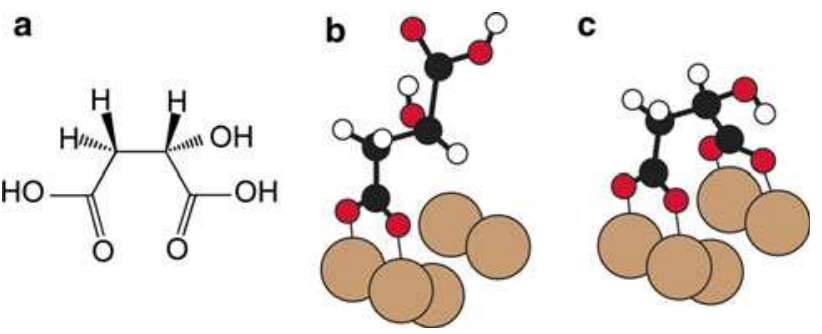

Fig. 1 Malic acid (a) on $\mathrm{Cu}(110)$ with one (b) or both carboxylates (c)

strongly depends on coverage, i.e., increases with increasing coverage. This is due to kinetic hindrance not allowing parts of the molecule in the close-packed layer to reach down to the surface for decomposition. At saturation coverage a maximum stabilization is achieved and the decomposition temperature is now far above the decomposition temperature for an isolated molecule. However, once decomposition is initiated, the increasing number of free sites affects in turn the decomposition rate. At first approximation, the rate of decomposition (decrease in coverage) depends then on the coverage $\theta$ (number of molecules) and the number of free sites $(1-\theta)[20]$ :

$-\mathrm{d} \theta / \mathrm{dt}=A \theta(1-\theta) \mathrm{e}^{-\mathrm{E} / \mathrm{RT}}$

More complicated models have been proposed as well, taking the shrinking island circumference into account [3336]. Due to the surface explosion chemistry of TA on $\mathrm{Cu}(110)$, we were able to distinguish between homochiral twodimensional (2D) crystals and heterochiral arrangements for the racemic analogue just by decomposition kinetics [20].

Here we present the thermal decomposition reaction of malic acid (MA) on $\mathrm{Cu}(110)$ that undergoes a surface explosion as well, but does not show differences between racemate and pure enantiomers. At monolayer saturation coverage MA is present in its single deprotonated form (Fig. 1b), no matter if the racemate or the pure enantiomers is adsorbed, and both systems show a $\mathrm{c}(2 \times 4)$ structure [37, 38]. During the decomposition a species is formed that is thermally more stable and decomposes at higher temperature. MA forms a large number of different structures on $\mathrm{Cu}(110)$. For the pure enantiomer we identified eleven different phases [37], while another four different phases were found for the racemate [38], suggesting heterochiral building motifs in the racemic layer. For both cases we recently identified via STM Cu adatom rows in the molecular layer, i.e., the copper substrate is reconstructed in a chiral fashion.

\section{Experimental}

The experiments have been carried out in a stainless steel ultrahigh vacuum (UHV) chamber ( $\mathrm{p}=2 \times 10^{-10} \mathrm{mbar}$ ), equipped with facilities for thermal desorption spectroscopy (TDS), low-energy electron diffraction (LEED), X-ray photoelectron spectroscopy (XPS) and reflectionabsorption infrared spectroscopy (RAIRS). The polished copper(110) single crystal (Matek, Germany) could be cooled and heated from 85 to $1000 \mathrm{~K}$. The in vacuo $\mathrm{Cu}(110)$ surface preparation, consisting of cycles of prolonged argon ion bombardment plus annealing, has been described in detail previously [39, 40]. After this treatment, the surface did not show any impurities in XPS and the LEED pattern consisted of a sharp and bright $(1 \times 1)$ structure with low background intensity. (S)-malic acid (Sigma-Aldrich, 98-100\%), (R)-malic acid (Sigma-Aldrich, 97\%) and the racemate (Sigma-Aldrich, 99\%) were evaporated from a multiple-cell evaporator $\left(\mathrm{T}=65^{\circ} \mathrm{C}\right)$. The $\mathrm{Cu}$ crystal temperature during deposition was, if not stated otherwise, held at room temperature. TDS has been performed with a heating rate of $4 \mathrm{~K} / \mathrm{s}$. The desorbing molecules were identified with a Pfeiffer Prisma 200 quadrupole mass spectrometer, which was located in a differentially pumped tube with a pinhole at the front, assuring that only molecules desorbing from the sample were detected during a TDS run. RAIRS has been performed with the Bruker Vertex 70 vacuum spectrometer with external detector. Separated by $\mathrm{CaF}_{2}$ windows from the UHV, the light path was pumped down to 0.1 mbar. Angle of incidence and of reflection in the RAIRS set-up were both $83^{\circ}$ with respect to the surface normal. XPS peak fitting has been performed after Shirley background subtraction. We use here absolute coverage values $\theta$, i.e., molecules per surface atoms, as well as relative coverage in monolayers (ML; $1 \mathrm{ML} \approx \theta=0.25$ ).

\section{Results}

\subsection{Thermal Desorption Spectroscopy}

Figure 2 shows a TDS series for $\mathrm{CO}_{2}$ evolution from $(R)$ MA on $\mathrm{Cu}(110)$ with increasing coverage. Two peaks are observed, one shifting strongly with increasing coverage from 450 to $512 \mathrm{~K}$, another at $570 \mathrm{~K}$ (Fig. 2, inset) that does not shift and is saturated already at small coverage. We note that molecular $\mathrm{CO}_{2}$ desorption from $\mathrm{Cu}(110)$ occurs at cryogenic temperatures, i.e., $\mathrm{CO}_{2}$ itself is physisorbed [39]. Consequently the $\mathrm{CO}_{2}$ signals here are due to decomposition of malate. The low temperature decomposition peak not only shifts to higher temperatures, but also shows a dramatic decrease in peak width and is therefore a clear indication for surface explosion kinetics.

After this first explosion decomposition step a molecular fragment is still left on the surface that undergoes again decomposition at higher temperature into $\mathrm{CO}_{2}$ as well. In contrast to the low temperature peak, the width of the 


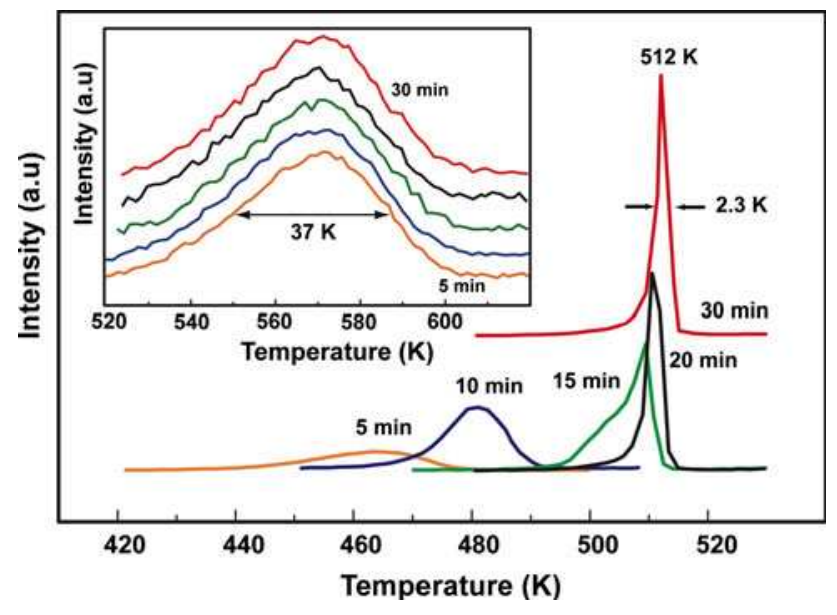

Fig. 2 Series of TD spectra for $\mathrm{CO}_{2}$ (44 amu mass fragment) with increasing coverage of $(R)$-MA. The deposition times are indicated. At monolayer saturation the narrow peak indicates the surface explosion kinetics

decomposition peaks is not as narrow. Moreover, the ratio of mass 28 amu (CO signal, not shown here) to $44 \mathrm{amu}$ $\mathrm{CO}_{2}$ desorption is substantially higher. Considering the high electron impact energy of the mass spectrometer it is safe to assume identical fragmentation rates for $\mathrm{CO}_{2}$ into $\mathrm{CO}$ for the small temperature difference of the two peaks. This allows, in turn, the conclusion that $\mathrm{CO}$ is intrinsically formed in the second decomposition step at the surface. Another striking difference is that no $\mathrm{H}_{2} \mathrm{O}$ desorption can be observed for the second peak at $570 \mathrm{~K}$ (Fig. 3). The ratio of $\mathrm{CO}_{2}$ formed in the two decomposition reactions, i.e., areas under the TDS traces, is 0.5 (peak at $570 \mathrm{~K}$ divided by peak at $512 \mathrm{~K}$ ) at saturation. The TDS results for racemic MA do not show any differences with respect to the pure enantiomers. In order to understand the

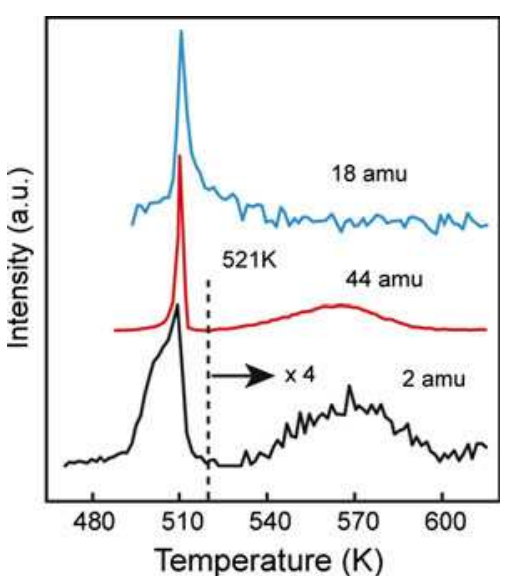

Fig. 3 TD spectra for $\mathrm{CO}_{2}(44 \mathrm{amu}), \mathrm{H}_{2} \mathrm{O}(18 \mathrm{amu})$ and $\mathrm{H}_{2}(2 \mathrm{amu})$ of a saturated monolayer of $(S)$-MA. $\mathrm{H}_{2} \mathrm{O}$ is not observed in the second peak. Spectra for $\mathrm{CO}_{2}$ and $\mathrm{H}_{2}$ above $521 \mathrm{~K}$ have been magnified by a factor of four observed decomposition steps, we performed RAIRS and XPS studies at the corresponding temperatures.

\subsection{X-ray Photoelectron Spectroscopy}

The XPS oxygen 1s signal of a complete monolayer is shown in Fig. 4a. As previously identified via C 1s XPS and RAIRS, at this coverage basically only monomalate is present at the surface $[37,38]$. The additional intensity at the high binding energy side in spectrum Fig. 4a is due to the carboxyl group not interacting with the surface. At $67 \%$ of the monolayer $(R)$-MA forms, like TA on $\mathrm{Cu}(110)$, a $(12,-82)$ structure with both carboxylates bound to the surface (for more details about the matrix notation see Ref. [41]). The fit for the bimalate (Fig. 4b) shows therefore two peaks in a ratio of $4: 1$, representing the carboxylate and hydroxyl O-atoms, respectively. The peak energies are $532.7 \mathrm{eV}(\mathrm{HO}-\mathrm{CH})$ and $531.4 \mathrm{eV}\left(\mathrm{COO}^{\delta-}\right)$. Upon heating to $520 \mathrm{~K}$, the signal of the $\mathrm{OH}$ group disappears, while a smaller signal for the carboxylate oxygen atoms is still present. At temperatures above $600 \mathrm{~K}$ no oxygen is left on the surface.

The corresponding carbon 1s spectra are shown in Fig. 5. Again, the room temperature spectrum reflects the monomalate species [37, 38]. Heating to $521 \mathrm{~K}$ increases the intensity at the low energy side, which points to more residual carbon at the surface. In addition, the $\mathrm{C} 1 \mathrm{~s}$ components observed for the intact molecule are still present. These are $286.2 \mathrm{eV}(\mathrm{HC}-\mathrm{OH}), \quad 287.6 \mathrm{eV} \quad\left(\mathrm{COO}^{\delta-}\right)$ $288.7 \mathrm{eV}(\mathrm{COOH}), 284.4 \mathrm{eV}\left(\mathrm{CH}_{2}\right)$ and 283.4 (residual carbon). For better comparison the spectra of the heated samples were magnified by a factor two. At temperatures above the second decomposition step at $570 \mathrm{~K}$, only the $\mathrm{CH}_{2}$ peak is left (Fig. 5c). The higher energy peaks of this $800 \mathrm{~K}$ spectrum are actually background noise, which also applies to the small peaks of the $521 \mathrm{~K}$ spectrum (Fig. 5b).

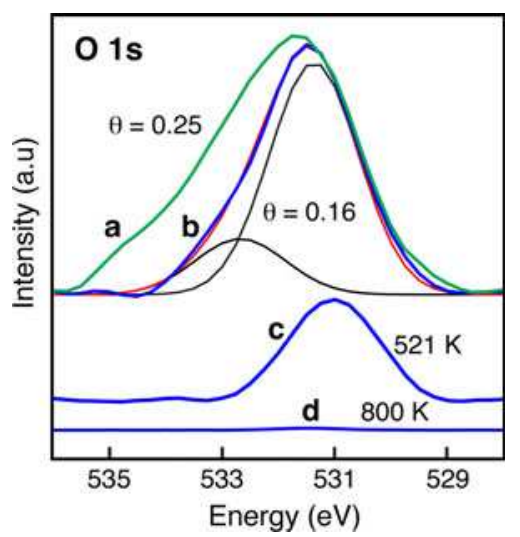

Fig. 4 O 1s XP spectra of a saturated monolayer $(a)$, a bimalate layer $(b)$, and after annealing to $521 \mathrm{~K}(c)$ and $800 \mathrm{~K}(d)$ 


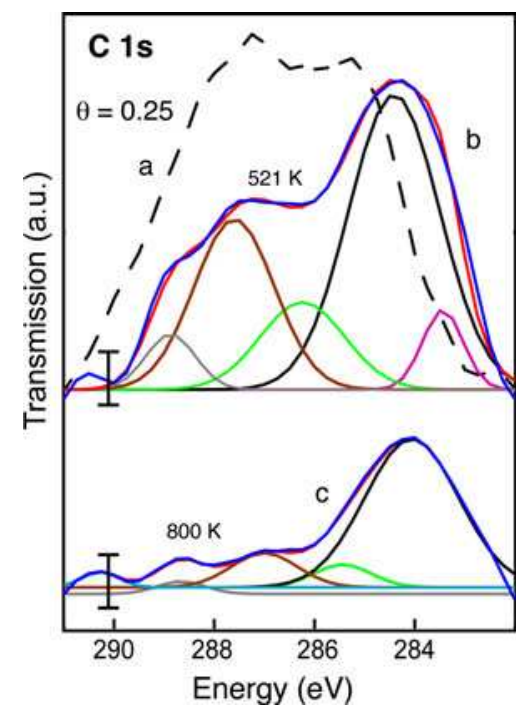

Fig. $5 \mathrm{C}$ 1s XP spectra for the saturated monolayer (dashed line in $a$ ), and the sample after annealing at $521 \mathrm{~K}(b)$ and $800 \mathrm{~K}(c)$. Error bars indicate the noise of the original, not smoothed spectra

In addition, we cannot exclude that carbon segregates into the $\mathrm{Cu}$ bulk to some extent at $800 \mathrm{~K}$.

\subsection{Reflection-Absorption Infrared Spectroscopy}

Beyond the chemical analysis provided by XPS, this surface IR spectroscopic method allows to identify the adsorption mode of the intact molecule as well as molecular fragments at the surface after thermal-induced decomposition. Figure 6 shows the spectra for the saturated monolayer at room temperature and after thermal treatment at 521 and $800 \mathrm{~K}$. Basically the following vibrational modes are identified: $\mathrm{C}=\mathrm{O}$ stretching mode $\left(v^{\mathrm{C}=\mathrm{O}}\right)$ at $1700 \mathrm{~cm}^{-1}$, symmetric OCO stretching mode $\left(v_{\mathrm{s}}^{\mathrm{OCO}}\right)$ of the carboxylate at $1432 \mathrm{~cm}^{-1}$, the $\mathrm{CH}$ deformation band $\left(\delta^{\mathrm{CH}}\right)$ at 1306 to $1322 \mathrm{~cm}^{-1}$, and $\mathrm{C}-\mathrm{H}$ stretching modes at $2967 \mathrm{~cm}^{-1}, 2930 \mathrm{~cm}^{-1}$, and $2863 \mathrm{~cm}^{-1}$. The room temperature spectrum (Fig. 6a) is dominated by monomalate, indicated by the strong $\mathrm{C}=\mathrm{O}$ stretching mode. However, the broad feature at $1432 \mathrm{~cm}^{-1}$ probably contains two bands of the symmetric carboxylate vibration $v_{\mathrm{s}}^{\mathrm{OCO}}$ at 1436 and $1419 \mathrm{~cm}^{-1}$. The latter is characteristic for bimalate which is difficult to be excluded in general under our preparation conditions.

After the surface explosion reaction the $\mathrm{C}-\mathrm{H}$ stretching modes are all still observed, while the $\mathrm{C}=\mathrm{O}$ stretching mode disappeared. The broad bump at $1693 \mathrm{~cm}^{-1}$ has a shoulder at lower wavenumbers that could stand for a monodentate carboxylate formation. Monodentate formation has been observed recently after prolonged annealing of rac-MA at lower temperatures [38]. The $v_{\mathrm{s}}^{\mathrm{OCO}}$ mode of the bidentate carboxylate disappeared at $521 \mathrm{~K}$ and

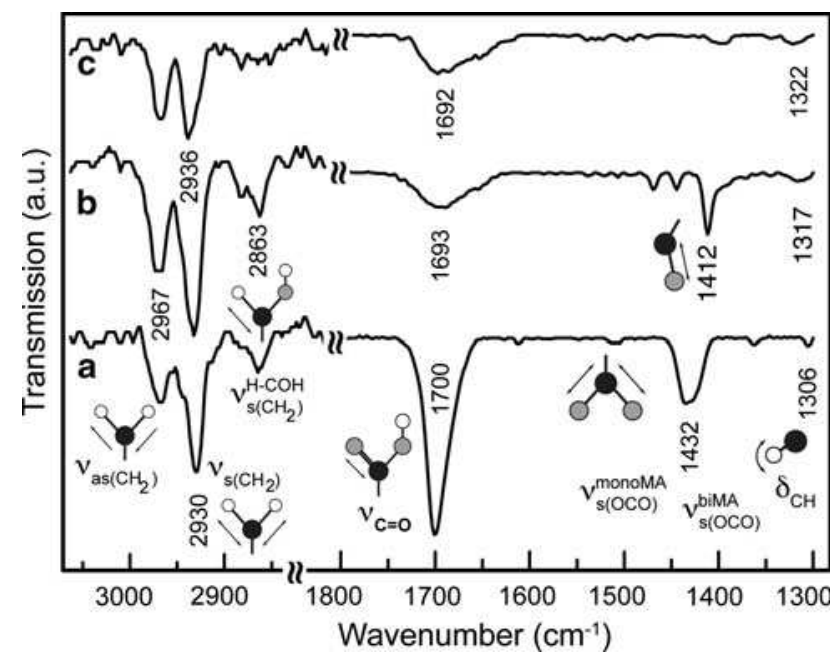

Fig. 6 RAIR spectra before $(a)$ and after heating to $521 \mathrm{~K}(b)$ and $800 \mathrm{~K}(c)$

therefore a $\mathrm{C}-\mathrm{O}$ stretching mode at $1412 \mathrm{~cm}^{-1}$ appeared (Fig. 6a). After further heating to $800 \mathrm{~K}$ (Fig. 6c) only the symmetric and antisymmetric $\mathrm{C}-\mathrm{H}$ stretching vibrations are observed. The $\mathrm{H} \leftrightarrow \mathrm{COH}$ stretching mode at $2863 \mathrm{~cm}^{-1}$ (or a group of symmetric and antisymmetric $\mathrm{C}-\mathrm{H}$ modes at that carbon between 2880 and $2850 \mathrm{~cm}^{-1}$ ) disappeared at $800 \mathrm{~K}$ as well. The broad signal at $1693 \mathrm{~cm}^{-1}$ is still observed after heating to $800 \mathrm{~K}$, when XPS showed that no oxygen is left at the surface. Therefore, this broad feature must be an artefact that cannot be explained with the $\mathrm{C}=\mathrm{O}$ vibration.

\section{Discussion}

From all observation it is difficult to establish a clear decomposition scenario. TDS and XPS show that in the surface explosion decomposition step at $511 \mathrm{~K}$ only $66 \%$ of the carboxylate groups leave the surface as $\mathrm{CO}_{2}$. The TDS peak at $570 \mathrm{~K}$ shows no explosion characteristics, does not have $\mathrm{H}_{2} \mathrm{O}$ as product, but a higher intensity of the $28 \mathrm{amu}$ fragment (CO). At least one species left after the explosion step contains a carboxyl group leading to $\mathrm{CO}_{2}$ in the second step. Another (or the same) species has a $\mathrm{C}-\mathrm{O}$ group with the single bond between $\mathrm{C}$ and $\mathrm{O}$. However, an $\mathrm{OH}$ group is not identified via XPS. ${ }^{1}$ Only $\mathrm{CH}_{2}$ groups are still observed after heating to $800 \mathrm{~K}$. Other butanedioic acids, like TA and SU, show surface explosion as well, but decompose in one step only. This leads us to the following decomposition scenario, taking the lower symmetry of MA into account. For monomalate two different possibilities

\footnotetext{
${ }_{1}$ The background signal for $\mathrm{OH}$ in RAIRS was too high to address this question via this method.
} 


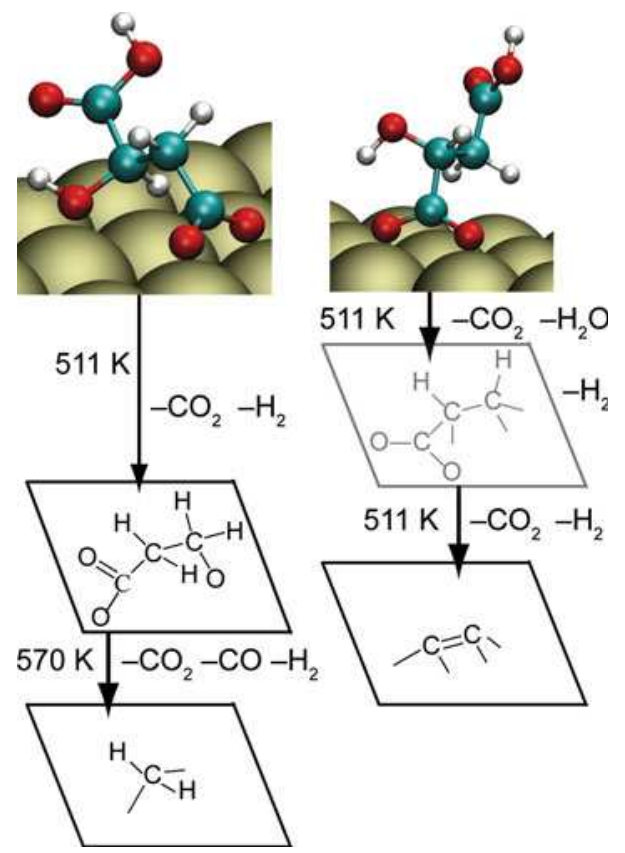

Fig. 7 Decomposition scheme explaining the observed desorbing and remaining fragments. MA can in principle be bound in two different ways in the monomalate mode

exist, while succinate and tartrate do not show such differences.

Figure 7 shows the two possibilities and possible consequences for decomposition pathways. With the $\mathrm{OH}$ group in $\beta$-position (with respect to the carboxylate group in contact with the surface) this group can reach down to the surface in order to establish another surface bond. Previous DFT calculations showed that this would have an additional stabilization effect of $0.54 \mathrm{eV}$ [37]. The most stable configuration with the hydroxyl at the $\alpha$-position (Fig. 7, top right) has an intramolecular hydrogen bond with a carboxylate oxygen. Although these calculations have been performed for single molecules, therefore not taking intermolecular bonding in the close-packed monolayer into account, they may become valid for the initial situation of the explosion chemistry when more space is generated. The $\beta$-hydroxyl malate becomes stabilized by forming an additional O-surface bond after losing the hydrogen. The $\alpha$-hydroxyl malate, devoid of such pathway, decomposes into water, carbon dioxide, hydrogen and graphitic carbon. The stabilized intermediate decomposes at $570 \mathrm{~K}$ into $\mathrm{CO}$, $\mathrm{H}_{2}$ and $\mathrm{CO}_{2}$ and methylene groups are left at the surface. This tentative decomposition model does explain most, but not all, of the observations made here.

The surface explosion temperatures for tartaric acid were different for racemate and pure enantiomers at identical coverage and adsorbate lattice periodicity. This was explained by the presence of a heterochiral lattice in case of the racemate, excluding a conglomerate of homochiral domains. Transferring this logic to MA, one would come to the conclusion that the racemate appears in homochiral domains. However, STM showed differences in short range order for both $\mathrm{c}(2 \times 4)$ lattices that points to a heterochiral structure for the racemate as well [37, 38]. Apparently, heterochiral $\alpha-/ \beta$-hydroxyl MA pairs can be better aligned without any consequences in decomposition kinetics.

\section{Conclusions}

Malic acid decomposes, as other butanedioic acids do on $\mathrm{Cu}(110)$, in an autocatalytic reaction, called surface explosion. In contrast to tartaric acid and succinic acid, during this fast reaction one or more stable surface species survive at the surface and decompose at higher temperature into hydrocarbon fragments. No differences in decomposition temperature for racemate and pure enantiomers have been identified for malic acid.

Acknowledgments Support by the Schweizerischer National Fonds is gratefully acknowledged. We thank D. Passerone for preparing the colored part of Fig. 7.

\section{References}

1. Sheldon RA (1993) Chiral technologies: industrial synthesis of optically active compounds. M Dekker, New York

2. Mallat T, Orglmeister E, Baiker A (2007) Chem Rev 107:4863

3. Baiker A (1997) J Mol Catal A Chem 115:473

4. Izumi Y (1983) Adv Catal 32:215

5. Keane MA (1997) Langmuir 13:41

6. Blaser HU (1991) Tetrahedron Asymmetr 2:843

7. Ertl G (2007) Nobel Lecture (2008) Angew Chem Int Ed 47:3524

8. Ernst K-H (2006) Top Curr Chem 265:209

9. Raval R (2009) Chem Soc Rev 38:707

10. Jones TE, Baddeley CJ (2002) Surf Sci 513:453

11. Jones TE, Baddeley CJ (2002) Surf Sci 519:237

12. Ma Z, Lee I, Kubota J, Zaera F (2004) J Mol Catal A Chem 216:199

13. Behzadi B, Ferri D, Baiker A, Ernst K-H (2007) Appl Surf Sci 253:3480

14. Humblot V, Haq S, Muryn C, Hofer WA, Raval R (2002) J Am Chem Soc 124:503

15. Ortega Lorenzo M, Haq S, Bertrams T, Murray P, Raval R, Baddeley CJ (1999) J Phys Chem B 103:10661

16. Ortega Lorenzo M, Baddeley CJ, Muryn C, Raval R (2000) Nature 404:376

17. Barbosa LAMM, Sautet P (2001) J Am Chem Soc 123:6639

18. Fasel R, Wider J, Quitmann C, Ernst K-H, Greber T (2004) Angew Chem Int Ed 43:2853

19. Hermse CGM, van Bavel AP, Jansen APJ, Barbosa LAMM, Sautet P, van Santen RA (2004) J Phys Chem B 108:11035

20. Romer S, Behzadi B, Fasel R, Ernst K-H (2005) Chem Eur J 11:4149

21. Behzadi B, Romer S, Fasel R, Ernst K-H (2004) J Am Chem Soc 126:9176

22. Parschau M, Behzadi B, Romer S, Ernst K-H (2006) Surf Interface Anal 38:1607 
23. Humblot V, Ortega Lorenzo M, Baddeley CJ, Haq S, Raval R (2004) J Am Chem Soc 126:6460

24. Parschau M, Romer S, Ernst K-H (2004) J Am Chem Soc 126:15398

25. Parschau M, Kampen T, Ernst K-H (2005) Chem Phys Lett 407:433

26. Fasel R, Parschau M, Ernst K-H (2006) Nature 439:449

27. Parschau M, Fasel R, Ernst K-H (2008) Cryst Growth Des 8:1890

28. Haq S, Liu N, Humblot V, Jansen APJ, Raval R (2009) Nat Chem 1:409

29. Roth C, Passerone D, Ernst K-H (2010) Chem Commun 46:8645

30. Falconer JL, Madix RJ (1974) Surf Sci 46:473

31. McCarty J, Falconer JL, Madix RJ (1973) J Catal 30:235

32. Madix RJ, Falconer JL, Suszko AM (1976) Surf Sci 54:6
33. Li Y, Bowker M (1993) Surf Sci 285:219

34. Cassidy TJ, Allen MD, Li Y, Bowker M (1993) Catal Lett 21:321

35. Aas N, Bowker M (1993) J Chem Soc Farad Trans 89:1249

36. Bowker M, Morgan C, Couves J (2004) Surf Sci 555:145

37. Roth C, Passerone D, Merz L, Parschau M, Ernst K-H (2011) J Phys Chem C 115:1240

38. Roth C, Parschau M, Ernst K-H (2011) ChemPhysChem 12:1572

39. Ernst K-H, Schlatterbeck D, Christmann K (1999) Phys Chem Chem Phys 1:4105

40. Parschau M, Fasel R, Ernst K-H, Gröning O, Brandenberger L, Schillinger R, Greber T, Seitsonen A, Wu Y-T, Siegel JS (2007) Angew Chem Int Ed 46:8258

41. Merz L, Ernst K-H (2010) Surf Sci 604:1049 